\title{
Fragmentação florestal na Área de Proteção Ambiental de Tambaba, Paraíba, Brasil
}

\author{
Saara Souza Rodrigues ${ }^{\dagger 1}$, Cleber Salimon ${ }^{1} \&$ Saulo Roberto de Oliveira Vital $^{2}$
}

$(\dagger)$ In memoriam

(1) Universidade Estadual da Paraíba - Campus V, Centro de Ciências Biológicas e Sociais Aplicadas, Rua Horácio Trajano de Oliveira, Cristo Redentor 58071-160, João Pessoa, Paraíba, Brasil. E-mail: clebsal@ccbsa.uepb.edu.br

(2) Universidade Federal do Rio Grande do Norte, Centro de Ensino Superior do Seridó, Rua Joaquim Gregório, Penedo, Caicó 59.300-000, Rio Grande do Norte, Brasil. E-mail: srovital@gmail.com

Rodrigues S.S., Salimon C. \& Vital S.R.O. (2017) Fragmentação florestal na Área de Proteção Ambiental de Tambaba, Paraíba, Brasil. Pesquisa e Ensino em Ciências Exatas e da Natureza, 1(2): 86-94.

Resumo: Um dos ecossistemas brasileiros mais fragmentados, devido ao desmatamento histórico, é a Mata Atlântica, que abriga uma das maiores diversidades biológicas do planeta. A área e a forma destes fragmentos podem influenciar o efeito de borda sobre padrões e processos em um ecossistema florestal. $\mathrm{O}$ presente estudo mapeou e caracterizou a fragmentação florestal da Área de Proteção Ambiental de Tambaba (APA), no litoral sul da Paraíba, utilizando métricas da paisagem com o objetivo de verificar a efetividade da proteção ambiental na unidade de conservação. Para isto, foi feita uma classificação supervisionada por máxima verossimilhança, da cobertura do solo, a partir de imagens RapidEye em duas classes: (1) floresta (vegetação nativa); (2) não-floresta (todos outros tipos de cobertura). A análise métrica da paisagem (total de fragmentos, área núcleo, proporção de área núcleo por fragmento, entre outros) foi realizada com a extensão Patch Analyst em ambiente ArcGis. Da área total da APA (11.550 ha), 2.200 ha (19\%) foram classificados como floresta, distribuídos em 1.364 fragmentos. A área núcleo total variou de 1.470 (efeito de borda de $10 \mathrm{~m}$ ) a 370 ha (efeito de borda de $50 \mathrm{~m}$ ), proporcionando uma conservação real entre 13 e 3\% da área total. Estes resultados apontam para a necessidade de uma fiscalização intensa e rigorosa do cumprimento das leis, bem como um gerenciamento racional e participativo por meio dos órgãos públicos e do conselho consultivo da APA, para que se protejam os fragmentos remanescentes.

Palavras chave: Efeito de borda, conservação, métricas da paisagem, desmatamento.

\section{Forest fragmentation in the Environmental Protection Area of Tambaba, Paraíba, Brazil}

Abstract: One of the most fragmented ecosystems in Brazil is the Atlantic Rain Forest, due to centuries of deforestation along the coast which holds one of the world's greatest biodiversity. Landscape metrics and shape can impact on border effect on patterns and processes of a forested ecosystem. In this paper, we map and characterize the forest fragmentation of the Tambaba Environmental Protection Area (APA), on the coast of Paraíba State, Brazil, using landscape metrics to verify the effectiveness of this protected area. We conducted a land cover classification (supervised classification by maximum likelyhood, RapidEye imagery) into two categories (1) forest and (2) non forest. Landscape metrics (number of fragments, total core area, proportion of core area, among others) were calculated using ArcGis extension Patch Analyst. From the APA's total 11.550 ha, 2.200 ha were classified as forest (19\%), distributed in 1.364 fragments of different sizes. Total core area varied from 1.470 (10 m border effect) to 370 ha (50 m border effect), dependending on edge effect distance, which provides a true conservation of only 13 to $3 \%$ of the total APA. These results point to the necessity of an intense and rigorous surveillance of the compliance with laws, as well as a rational and participatory management, through the APA's management council and public agencies, in order to protect the remnant fragments.

Key words: Border effect, conservation, landscape metrics, deforestation. 


\section{Introdução}

Dentre as categorias de conservação do Sistema Nacional de Unidades de Conservação (SNUC), as Áreas de Proteção Ambiental (APA) tem por objetivo a proteção (ecossistemas, biota e serviços ambientais) e também seu uso sustentável (Brasil 2000). Porém, devido às suas restrições mais brandas quanto aos usos permitidos, muitas APAs apresentam diversos e variados graus de impacto antropogênico. Um dos efeitos antropogênicos mais notórios na paisagem é a fragmentação dos ecossistemas naturais (Haddad et al. 2015) e o aumento da matriz antropogênica (Murcia 1995; Metzger 2001).

Um dos ecossistemas brasileiros mais fragmentados, devido ao desmatamento histórico, é a Mata Atlântica, que abriga uma das maiores diversidades biológicas do planeta. Estima-se que mais de $80 \%$ dos fragmentos são menores que 50 ha e seu centro encontra-se a menos de $100 \mathrm{~m}$ da borda (Ribeiro et al. 2009).

As métricas de área e de forma dos fragmentos podem influenciar o efeito de borda sobre padrões e processos em um ecossistema florestal (Herrmann et al. 2005; Nascimento \& Laurance 2006). Por exemplo, quanto menor é o tamanho, maior é a relação borda-área; e se mais irregular e menor é o fragmento florestal, maior será sua tendência a sofrer com a intensidade dos efeitos de temperatura, luminosidade, estresse hídrico e incidência de ventos (Périco et al. 2005; Stevens 2014).

Os índices de área núcleo são referências de qualidade de habitats e a métrica de proximidade associa-se a distância entre as manchas adjacentes e pode indicar a necessidade de implantar elementos de conexão entre os fragmentos, como corredores ecológicos. Nesse sentido, quanto menor a distância entre os fragmentos, maior a possibilidade de dispersão das espécies (Lang \& Blaschke 2009).

A utilização de Sistema de Informação Geográfica (SIG) e de determinação de métricas da paisagem (Bierregaard et al. 1992), permite detectar, analisar, mapear e quantificar os padrões espaciais da fragmentação e suas variações ao longo do tempo, subsidiando o monitoramento do uso e cobertura do solo e também a gestão de recursos ambientais em áreas protegidas (Vetorazzi 1996; Rosa 2005).

Estudos sobre a quantificação estrutural dos fragmentos florestais com uso de índices da paisagem ainda são escassos no Estado da Paraíba. Esse tipo de mensuração permite retratar o estado da vegetação local, oferecendo informações para estimar as alterações no padrão de distribuição espaço-temporal da cobertura florestal e inferir sobre a qualidade ambiental da área (Guisard \& Kuplich 2008; Ribeiro et al. 2009; Ducatti et al. 2011).

Com base neste contexto, o presente estudo mapeou e caracterizou a fragmentação florestal atual da Área de Proteção Ambiental de Tambaba, no litoral sul da Paraíba, utilizando métricas da paisagem com três metragens diferentes de efeito de borda com o objetivo de verificar a efetividade da proteção ambiental na unidade de conservação.

\section{Material e Métodos}

\section{Área de estudo}

A Área de Proteção Ambiental de Tambaba (doravante mencionada apenas como APA) localiza-se na Mesorregião da Zona da Mata Paraibana, abrangendo os municípios do Conde, Pitimbú e Alhandra, apresentando extensão territorial de 11.550 ha, situando-se entre as seguintes coordenadas geográficas: $07^{\circ} 25^{\prime} 00^{\prime \prime}-07^{\circ} 16^{\prime} 30^{\prime \prime} \mathrm{S}$ de latitude e $34^{\circ} 55^{\prime} 00^{\prime \prime}-34^{\circ} 47^{\prime} 30^{\prime \prime} \mathrm{O}$ de longitude (Figura 1), Decreto Estadual PB no 22.882.

Em relação à geologia regional, a APA se encontra inserida no contexto da Bacia Sedimentar da Paraíba, representada por calcários argilosos cinzentos de deposição marinha rasa; e a Formação Maria Farinha, composta por calcários recifais e dolomitos detríticos (Barbosa et al. 2003; Barbosa et al. 2007; Lima-Filho 2005). A região costeira é composta por diferentes elementos da paisagem, como falésias esculpidas em sedimentos da Formação Barreiras, que apresentam elevado grau de erosão devido aos processos da dinâmica continental. $O$ padrão de 
rede de drenagem e o terreno da área possuem variações em densidade e altitude, respectivamente, evidenciando a existência de áreas de relevo soerguidos ou rebaixados, em função da tectônica regional, predominando o padrão tabular (Furrier et al. 2006).
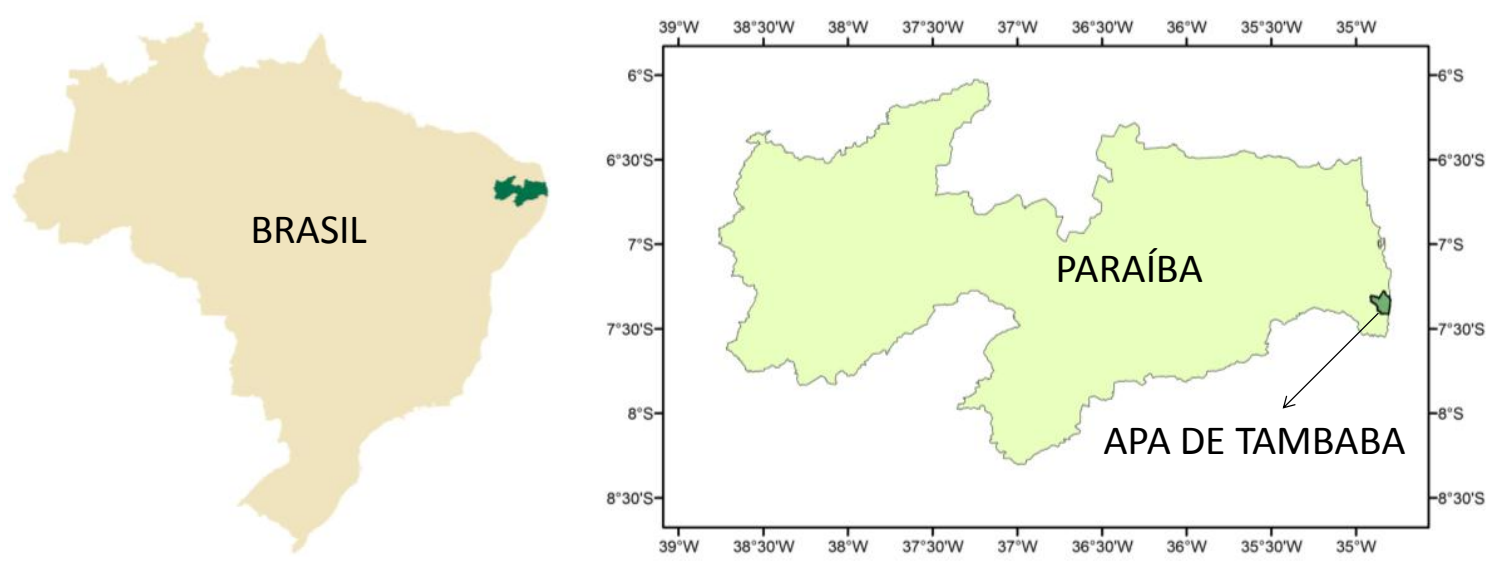

Figura 1. Localização geográfica da APA de Tambaba no Estado da Paraíba, Nordeste do Brasil.

Segundo a classificação de Köppen, o clima predominante é do tipo As' Tropical quente e úmido, com precipitação média variando entre 500 a $800 \mathrm{~mm} / \mathrm{ano}$. A temperatura média é de $26^{\circ} \mathrm{C}$ e a umidade relativa do ar é de $80 \%$. O regime de chuvas é bem distribuído ao longo do ano devido à influência das massas de ar equatorial atlântica, constituídas pelos ventos alísios do sudeste (Ferreira \& Mello 2005).

A área onde está inserida a APA apresenta uma grande diversidade de solos, de natureza morfológica, física, química e mineralógica relevante. $\mathrm{O}$ tipo luvissolo abrange a maior parte da área, típico de ambiente semiárido, pouco profundo, rico em argila e nutrientes, com alta suscetibilidade a erosão; apresenta nítida diferenciação entre os horizontes no que se refere a cor, textura e estrutura. Em seguida, ocorrem os solos da classe neossolos com características que variam bastante quanto aos sedimentos que o compõe, fertilidade natural, capacidade de retenção de água e teor de matéria orgânica. Ainda ocorrem na área o tipo espodossolo, predominante nos ambientes de restingas e tabuleiros costeiros, de textura arenosa e baixa fertilidade. Por fim, o local compreende os solos do tipo organossolo, característico de manguezal com alto teor de matéria orgânica, alta capacidade de retenção de água e fertilidade natural (Brasil 2014).

Considerando os diferentes tipos de vegetação nativa, há uma predominância de floresta estacional semidecidual, embora no passado deva ter existido manchas de florestas ombrófila, além das composições pioneiras de restingas e manguezais (Brasil 2010). Algumas espécies vegetais típicas e com maiores valores de importância na região são Tapirira guianensis, Sacoglottis mattogrossensis, Byrsonima sericea, Abarema cochliacarpos, Myrcia sp., Apuleia leiocarpa, Lecythis sp., Anacardium occidentale, Chaetocarpus myrsinites e Stryphnodendron pulcherrimum (SUDEMA 2011).

\section{Procedimentos Metodológicos}

O mapeamento de cobertura do solo foi realizado com duas imagens do sensor Rapideye (cenas 3A 2535706, 18314655 e 3A 2535606, 15470183) abrangendo a APA de Tambaba. As imagens foram obtidas no site do Geo Catálogo, do Ministério do Meio Ambiente (http://geocatalogo.mma.gov.br/). Para a seleção destas, foi utilizado o critério de cobertura de nuvens, sendo escolhidas aquelas que apresentaram cobertura mínima (menos de 5\%) na área referente de estudo.

Foram usadas três bandas de comprimentos $440-510 \mathrm{~nm}$ (azul); 520-590 nm (verde) e 630-685 nm (vermelho). As imagens das duas cenas foram unidas e equalizadas, utilizando algoritmo Geographic Imager no programa Photoshop (Avenza Systems 2014). Após a 
equalização, foi feita uma ampliação de contraste, utilizando uma função de aumento linear no SPRING (Camara et al. 1996). Posteriormente, utilizou-se de um arquivo shape de delimitação da APA para recortar da imagem composta a área referente desta (SUDEMA 2015). Esta imagem recortada foi então utilizada para uma classificação da cobertura do solo em duas classes: (1) floresta; (2) não-floresta. Para o presente estudo, floresta é qualquer vegetação com indivíduos predominantemente acima de $8 \mathrm{~m}$ de altura, cujas copas se tocam, formando um dossel (IBGE 2012). Desta forma, esta definição operacional é bem abrangente e não distingue florestas secundárias de florestas maduras, nem objetivamos neste estudo identificar diferentes estágios sucessionais. Toda outra forma de cobertura do solo (agricultura, corpos d'água, pastagens, áreas urbanas) foram classificadas como não-floresta, uma vez que não existem florestas implantadas ou monoculturas arbóreas.

Após esta definição operacional das classes, foram criados 88 arquivos de assinatura espectral, obtida por meio de coletas de padrões amostrais, que posteriormente foram utilizados para gerar uma classificação supervisionada, por máxima verossimilhança, utilizando-se as bandas do visível (azul, verde e vermelho). Após estes procedimentos, foi gerada uma matriz de confusão, baseada em verificação em campo de 60 pontos, e calculado o índice de Kappa (Landis \& Koch 1977), para aferição da acurácia da classificação.

A métrica da paisagem foi realizada com a extensão Patch Analyst (Elkie et al. 1999), no ArcGis 9.0 (ESRI 2010). Os seguintes atributos da paisagem foram analisados no presente trabalho: Área total de floresta; Área núcleo total; Porcentagem de área núcleo em relação a área total florestal; Porcentagem de área núcleo em relação a área da APA; Número total de fragmentos; Total de fragmentos com área núcleo; Porcentagem de fragmentos com área núcleo; Tamanho médio da área núcleo; Número de fragmentos maiores que 1 ha; Área total de fragmentos maiores que 1 ha; Distância média entre fragmentos; Distribuição espacial dos fragmentos. Operacional e conceitualmente, consideramos os fragmentos com menos de 1 ha fragmentos muito pequenos.

Embora neste estudo não seja feita uma análise dos efeitos de borda na biota ou em fatores ambientais, estimamos o tamanho real de área conservada, baseando-nos no conceito de "área núcleo", que consiste na área de um fragmento efetivamente protegida, subtraindo uma área perimetral tampão, sendo a borda sob influência da matriz externa (Lang \& Blaschke 2009). Com a aplicação desta borda, podemos verificar a área que não sofre (potencialmente) efeitos de fogo acidental na borda, pisoteio de gado, maior incidência de luz e temperatura e menor umidade relativa do ar. $\mathrm{O}$ tamanho real da borda varia muito entre diferentes ecossistemas, escalas espaciais, tipo de cobertura e uso, complexidade da matriz no entorno, entre diferentes pontos topográficos de um mesmo ecossistema, e seu efeito varia muito entre os diferentes grupos biológicos (Murcia 1995; Haddad et al. 2015). Em fungos, o efeito de borda é detectável somente até cerca de $10 \mathrm{~m}$ da borda, enquanto que o aumento da mortalidade de árvores pode ser detectado até $300 \mathrm{~m}$ da borda (Laurance et al. 2002). Desta forma, a definição de uma distância de efeito de borda é muito variável. Para fins operacionais, utilizamos as distâncias de 50, 30 e $10 \mathrm{~m}$ para verificar a sensibilidade da área total conservada como núcleo ao alcance dos efeitos de borda.

\section{Resultados}

\section{Classificação da Cobertura}

Dos 60 pontos aleatórios de checagem da classificação, somente quatro foram mal classificados e foram todos erros de omissão, onde florestas foram classificadas como não florestas. Porém, isto pode ser devido a diferença da data da imagem (2012) e data da observação em chão (2016), uma vez que eram florestas secundárias (verdade terrestre). A acurácia total da classificação da cobertura foi de 94\% (a partir da matriz confusão) e o Índice de Kappa foi de 0.86. Desta forma, tanto a classificação da cobertura de solo, quanto às análises de métrica da paisagem são representativas da realidade local. 
Da área total da APA (11.550 ha), 2.200 ha (19\%) foram classificados como floresta, mesmo utilizando uma definição bem ampla para esta classe de cobertura (ver Material e Métodos). Não houve um agrupamento claro de fragmentos em nenhuma região da APA (Figura 2A). Observa-se um adensamento de fragmentos próximos das redes de drenagem, mas existem também alguns poucos fragmentos maiores que se situam mais distantes dos pequenos rios.
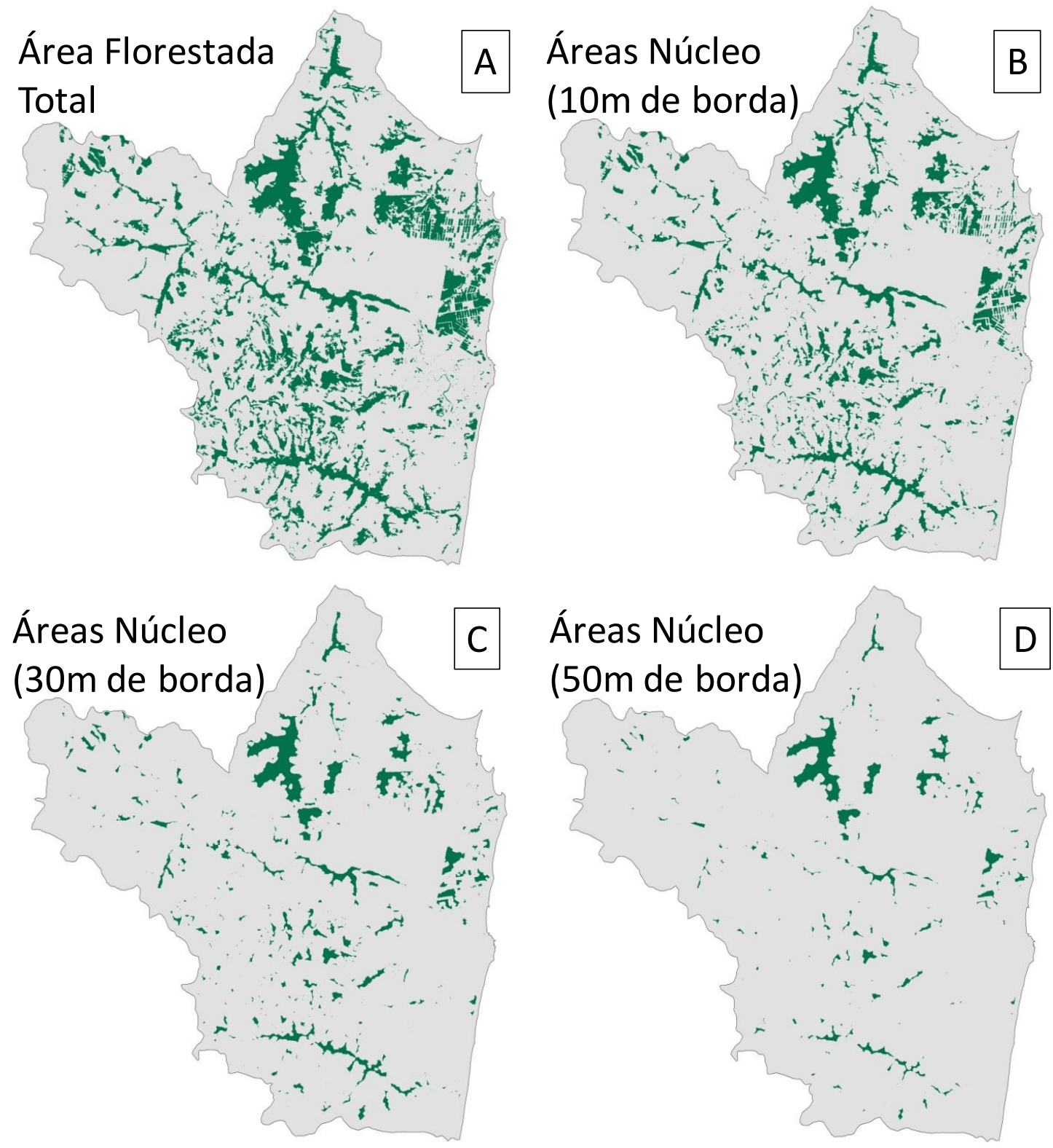

Figura 2. Área de Proteção Ambiental de Tambaba, Paraíba, Nordeste do Brasil. Os quatro mapas comparativos, ilustrando a quantidade de cobertura florestal, desde a área total florestada (A), com as simulações de diferentes profundidades de efeito de borda (B, C e D).

\section{Métricas da Paisagem}

A área total de vegetação arbórea nativa na APA encontra-se dividida em 1.364 fragmentos, dos quais $82 \%$ tem uma área de até 1 ha, $16 \%$ até 10 ha e $2 \%$ até 100 ha, sendo que, somente três fragmentos tem mais que 100 ha. Esta distribuição de frequência demonstra que além de altamente fragmentada, a paisagem é composta majoritariamente por fragmentos muito pequenos. 
A soma das áreas núcleo variou de 1.470 ha (borda de $10 \mathrm{~m}$ ) a 370 ha (borda de $50 \mathrm{~m}$ ), proporcionando uma conservação real entre 13 e $3 \%$ da área total da APA. O número total de fragmentos com área núcleo foi maior na análise com borda de $10 \mathrm{~m}$ (729) e menor na análise com borda de 50 m (96). Embora a relação seja óbvia, somente com esta análise podemos saber a área total que realmente é conservada, dependendo da extensão do efeito de borda.

A quantidade e área total de fragmentos com mais de 1 ha de área núcleo foram $187 \mathrm{e}$ 1.323 ha (borda de $10 \mathrm{~m}$ ), 99 e 641 ha (borda de $30 \mathrm{~m}$ ), 46 e 330 ha (borda de $50 \mathrm{~m}$ ). A distância média entre as áreas núcleo dos fragmentos variou entre $105 \mathrm{~m}$ (borda de $10 \mathrm{~m}$ ) e $314 \mathrm{~m}$ (borda de $50 \mathrm{~m}$ ). Os valores e porcentagens para cada uma das análises estão na Tabela 1.

Tabela 1. Métricas da Paisagem na Área de Proteção Ambiental de Tambaba, Paraíba, Brasil, com a simulação do efeito de borda de três níveis de intensidade (50, 30 e $10 \mathrm{~m})$.

\begin{tabular}{lccc}
\hline \multicolumn{1}{c}{ Métrica } & Borda $\mathbf{5 0 ~} \mathbf{~ m}$ & Borda 30 m & Borda $\mathbf{1 0 ~ m}$ \\
\hline Área total da APA (ha) & 11550 & 11550 & 11550 \\
Área total de fragmentos (ha) & 2200 & 2200 & 2200 \\
Área núcleo total (ha) & 370 & 704 & 1470 \\
Porcentagem de floresta na APA & 19 & 19 & 19 \\
Porcentagem de área núcleo por área total florestada & 17 & 32 & 67 \\
Porcentagem de área núcleo na APA & 03 & 06 & 13 \\
Proporção média de área núcleo por fragmento & 14 & 27 & 41 \\
Número total de fragmentos & 1364 & 1364 & 1364 \\
Total de fragmentos com área núcleo & 96 & 244 & 729 \\
Número total de áreas núcleo & 231 & 595 & 1595 \\
Porcentagem de fragmentos com área núcleo & 07 & 18 & 53 \\
Tamanho médio de área núcleo (ha) & 1.6 & 1.2 & 0.9 \\
Número de fragmentos maiores que 1 ha & 46 & 99 & 187 \\
Área total de fragmentos maiores que 1 ha & 330 & 641 & 1323 \\
Distância média entre áreas núcleo dos fragmentos $(\mathrm{m})$ & 314 & 183 & 105 \\
\hline
\end{tabular}

\section{Discussão}

Os resultados da classificação da cobertura demonstram o grau de antropização da região, onde somente $19 \%$ da paisagem é composta por cobertura florestal, que possivelmente, foi cerca de $100 \%$ antes da colonização européia (Leal \& Câmara 2003). Ressalta-se que na presente classificação de "floresta" estão inclusas florestas secundárias, com alto grau de impacto humano; portanto, nosso resultado é conservador no que diz respeito a área de floresta na APA. Desta forma, o impacto humano na conservação da APA, em termos de área de floresta nativa e madura, é provavelmente muito maior do que o que fomos capazes de medir neste estudo. Uma classificação futura em diferentes estágios de sucessão e/ou graus de impacto será muito útil para o gerenciamento da APA.

No Sistema Nacional de Unidades de Conservação - SNUC (Brasil 2000), uma Área de Proteção Ambiental, por ser de uso sustentável, tem como finalidade conservar a biodiversidade e os serviços ambientais prestados pelo ecossistema, em propriedades tanto públicas quanto privadas e não há uma restrição explícita quanto ao uso, pois são permitidas atividades agropecuárias e industriais, além de adensamentos populacionais urbanos e rurais. Desta forma, o que restringe o seu desmatamento são as outras leis ambientais (Código Florestal: Lei $\mathrm{n}^{\circ}$ 12.727, de 17 de outubro de 2012; lei da Mata Atlântica, Lei $\mathrm{n}^{0}$ 11.428, de 22 de dezembro de 2006), como a Reserva Legal, Áreas de Preservação Permanentes (APPs), em áreas de declive acentuado ou margens de rios e nascentes.

Devido a este seu caráter pouco rígido quanto ao desmatamento e pelo fato de ter sido criada há menos de 20 anos (provavelmente boa parte do desmatamento ocorreu antes de 2000), a APA de Tambaba apresentou uma baixa cobertura florestal, fruto de a uma intensa atividade agroindustrial ao Norte, e a adensamentos populacionais e especulação imobiliária ao leste ao longo da faixa litorânea no município do Conde. 
Soma-se a esta baixa cobertura florestal, o alto grau de fragmentação da paisagem, pois o que resta de floresta está espalhado em 1.334 fragmentos, de tamanhos e formas variadas. Esta alta fragmentação é negativa para a conservação (Ribeiro et al. 2009), pois a região é anualmente assolada por vários incêndios intencionais, fora os acidentais em beira de estrada, além de outros efeitos negativos para a biodiversidade, devido ao efeito de borda. Por outro lado, se considerarmos que estes fragmentos são ao mesmo tempo fontes de propágulos para regeneração de novas áreas abandonadas, a sua existência pode ser considerada positiva, dentro de um contexto mais generalizado de desmatamento intensivo também fora da APA.

Em relação à aplicação de diferentes faixas de efeito de borda (Figura 2), se desconsiderarmos áreas com menos de 1 ha (maioria dos fragmentos), o total de áreas núcleo é somente 330 ha (para um efeito de borda de $50 \mathrm{~m}$; Tabela 1 ), o que corresponde a somente $3 \%$ da APA. Aqui, novamente, isto se deve ao fato de que a maior parte da cobertura florestal está em fragmentos muito pequenos, e provavelmente ineficazes para conservação da biodiversidade.

Mesmo considerando a menor faixa de efeito de borda $(10 \mathrm{~m})$, existem somente 187 fragmentos com mais de 1 ha de área núcleo, ou 14\% dos fragmentos. Fragmentos muito pequenos provocam uma diminuição do número de indivíduos de cada espécie, reduzindo a variabilidade genética das populações, até a perda de espécies na região, levando a extinções locais (Kageyama et al. 1998). Animais, por exemplo, precisam se deslocar em busca de água e alimentos, e frequentemente são atropelados nas estradas e rodovias que cortam a APA.

Os incêndios frequentes nos períodos de seca (observação pessoal) também são outra ameaça a estes pequenos fragmentos, pois com uma alta razão perímetro/área os mesmos podem ser inteiramente afetados pelo fogo, por não possuírem uma área núcleo.

Embora autores discutam e proponham diferentes métodos de estimar o tamanho mínimo viável de uma unidade de conservação (Smith et al. 2010; Pe'er et al. 2014), não existe um número mínimo absoluto e geral para todos grupos taxonômicos. Um exemplo disto é que para macacos neotropicais, a área mínima de conservação é de cerca de 11.000 ha (Brito \& Grelle 2006). Considerando que só existem três fragmentos com mais de 100 ha, a APA como toda é insuficiente para conservação de uma população viável de grandes primatas. $\mathrm{O}$ que de fato acontece na prática, uma vez que só existem relatos de primatas de pequeno porte na região da APA.

Alguns trabalhos isolados têm sido realizados para levantamento de fauna e flora na região da APA, mas poucos foram publicados e tem seus dados públicos (Oliveira-Filho \& Carvalho 1993; Torelli et al. 1997; Santana et al. 2008). A criação de uma base de dados sobre a biodiversidade dentro da APA, com georreferenciamento ligando tanto riqueza quanto abundância de espécies com fragmentos específicos, possibilitará em um futuro próximo um melhor gerenciamento e planejamento futuro, que pode ser incluído no Plano de Manejo da APA de Tambaba.

Com base nos resultados aqui apresentados, podemos concluir que a paisagem da APA de Tambaba encontra-se majoritariamente desmatada, e seus $19 \%$ de cobertura florestal encontra-se altamente fragmentado e sob intensa ameaça devido ao efeito de borda, que compromete entre 87 e $97 \%$ da vegetação florestal ainda existente e toda a fauna a ela associada. É questionável, portanto, a eficiência da APA em proteger os ecossistemas no seu interior.

Estes resultados apontam para a necessidade de uma fiscalização intensa e rigorosa do cumprimento das leis, a criação de planos de recuperação para áreas degradadas dentro da APA, bem como um gerenciamento racional e participativo através dos Órgãos Públicos e do Conselho Consultivo da APA, para que se proteja os fragmentos remanescentes.

\section{Agradecimentos}

Aos avaliadores anônimos pela revisão crítica do manuscrito. 


\section{Referências}

Avenza Systems (2014) Avenza Systems Inc. Toronto: Avenza Systems Inc. Disponível em: https://www.avenza.com/geographic-imager/ (Acessado em 15/03/2015).

Barbosa J.A., Neumann V.H., Lima-Filho M., Souza E.M. \& Morais M.A. (2007) Estratigrafia da Faixa Costeira Recife-Natal (Bacia da Paraíba e Plataforma de Natal), NE Brasil. Estudos Geológicos, 17(2): 03-28.

Barbosa J.A., Souza E.M., Lima-Filho M.F. \& Neumann V.H. (2003) A Estratigrafia da Bacia Paraíba: Uma Reconsideração. Estudos Geológicos, 13: 89-108.

Bierregaard Jr. R.O., Lovejoy T.E., Kapos V., Santos A.A. \& Hutchings R.W. (1992) The Biological Dynamics of Tropical Rain-forest Fragments. Bioscience, 42: 859-866.

Brasil (2000) LEI No 9.985, DE 18 DE JULHO DE 2000. Instituição do Sistema Nacional de Unidades de Conservação da Natureza - SNUC.

Brasil (2010) Mata Atlântica: patrimônio Nacional dos Brasileiros. Brasília: MMA. 408 p.

Brasil (2014) Solos do Nordeste. Recife: Embrapa Solos. 38 p.

Brito D. \& Grelle C.E.V. (2006) Estimating minimum area of suitable habitat and viable population size for the northern muriqui (Brachyteles hypoxanthus). Biodiversity \& Conservation, 15(13): 4197-4210.

Camara G., Souza R.C.M., Freitas U.M. \& Garrido J. (1996) SPRING: Integrating remote sensing and GIS by object-oriented data modelling. Computers \& Graphics, 20(3): 395-403.

Ducatti A., Périco E., Arend Ú., Cemin G., Haetinger C. \& Rempel C. (2011) Análise da Paisagem por Sistemas de Informação Geográfica (SIGs) e Métricas de Paisagem como Subsídio para a Tomada de Decisões em Nível Ambiental. Espacios, 32(1): 36-42.

Elkie P.C., Rempel R.S. \& Carr A. (1999) Patch analyst user's manual: a tool for quantifying landscape structure. Ontario: Ontario Ministry of Natural Resources, Boreal Science, Northwest Science \& Technology. Disponível em: www.uni-klu.ac.at/geo/lv_online/seminar20 02/pa_manual.pdf (Acessado em 10/04/2015).

ESRI (2010) ArcGIS Desktop: Release 9.0. Redlands, CA: Environmental Systems Research Institute.

Ferreira A.G. \& Mello N.G.S. (2005) Principais Sistemas Atmosféricos Atuantes sobre a Região Nordeste do Brasil e a Influência dos Oceanos Pacífico e Atlântico no Clima da Região. Revista Brasileira de Climatologia, 1(1): 15-28.

Furrier M., Araújo M.E. \& Meneses L.F. (2006) Geomorfologia e Tectônica da Formação Barreiras no Estado da Paraíba. Revista do Instituto de Geociências - USP, 6(2): 61-70.

Guisard D.M.P. \& Kuplich T.M. (2008) Fragmentação da Cobertura Florestal no Município de São José dos Campos (SP) entre 1973 e 2004. Geografia, 33(2): 319-329.

Haddad N.M., Brudvig L.A., Clobert J., Davies K.F., Gonzalez A., Holt R.D., Lovejoy T.E., Sexton J.O., Austin M.P., Collins C.D., Cook W.M., Damschen E.I., Ewers R.M., Foster B.L., Jenkins C.N., King A.J., Laurance W.F., Levey D.J., Margules C.R., Melbourne B.A., Nicholls A.O., Orrock J.L., Song D.-X. \& Townshend J.R. (2015) Habitat fragmentation and its lasting impact on Earth's ecosystems. Science Advances, 1(2): 2015;1:e1500052. doi: 10.1126/sciadv.1500052

Herrmann B.C., Rodrigues E. \& Lima A. (2005) A Paisagem como Condicionadora de Bordas de Fragmentos Florestais. Floresta, 35(1): 13-22.

IBGE - Instituto Brasileiro de Geografia e Estatística (2012) Manual Técnico da Vegetação Brasileira. Disponível em: https//biblioteca.ibge.gov.br/visualizacao/livros/liv63011.pdf (Acessado em 10/10/2013).

Kageyama P.Y., Gandara F.B. \& Souza L.D. (1998) Consequências genéticas da fragmentação sobre populações de espécies arbóreas. Série Técnica IPEF, 12(32): 65-70.

Landis J.R. \& Koch G.G. (1977) The Measurement of Observer Agreement for Categorical Data. Biometrics, 33(1): 159-174.

Lang S. \& Blaschke T. (2009) Análise da paisagem com SIG. São Paulo: Oficina de Textos. 424 p. 
Laurance W.F., Lovejoy T.E., Vasconcelos H.L., Bruna E.M., Didham R.K., Stouffer P.C., Gascon C., Bierregaard R.O., Laurance S.G. \& Sampaio E. (2002) Ecosystem Decay of Amazonian Forest Fragments: A 22-Year Investigation. Conservation Biology, 16(3): 605-618.

Leal C.G. \& Câmara I.G. (2003) The Atlantic Forest of South America: biodiversity status, threats, and outlook. Washington: Island Press. 488 p.

Metzger J.P. (2001) O que é Ecologia de Paisagens? Biota Neotropica, 1(1): 02-09.

Murcia C. (1995) Edge effects in fragmented forests: implications for conservation. Trends in Ecology \& Evolution, 10(2): 58-62.

Nascimento H.E.M. \& Laurance W.F. (2006) Efeitos de Área e de Borda Sobre a Estrutura Florestal em Fragmentos de Floresta de Terra-firme após 13-17 Anos de Isolamento. Acta Amazônica, 36(2): 183-192.

Oliveira-Filho A.T. \& Carvalho D.A. (1993) Florística e fisionomia da vegetação no extremo Norte do litoral da Paraíba. Revista Brasileira de Botânica, 16(1): 115-130.

Pe'er G., Tsianou M.A., Franz K.W., Matsinos Y.G., Mazaris A.D., Storch D., Kopsova L., Verboom J., Baguette M., Stevens V.M. \& Henle K. (2014) Toward better application of minimum area requirements in conservation planning. Biological Conservation, 170: 92-102.

Périco E., Cemin G., Lima D.F.B. \& Rempel C. (2005) Efeitos da Fragmentação de Hábitats sobre Comunidades Animais: utilização de sistemas de informação geográfica e de métricas de paisagem para seleção de áreas adequadas a testes (p. 2339-2346). In: Epiphanio J.G.N. (Org.). XII Simpósio Brasileiro de Sensoriamento Remoto. Goiânia: SBSR.

Ribeiro M.C., Metzger J.P., Martensen A.C., Ponzoni F.J. \& Hirota M.M. (2009) The Brazilian Atlantic Forest: How much is left, and how is the remaining forest distributed? Implications for conservation. Biological Conservation, 142(6): 1141-1153.

Rosa R. (2005) Geotecnologias na Geografia Aplicada. Revista do Departamento de Geografia, 16: 81-90.

Santana G.G., Vieira W.L.S., Pereira-Filho G.A., Delfim F.R., Lima Y.C.C. \& Vieira K.S. (2008) Herpetofauna em um fragmento de Floresta Atlântica no Estado da Paraíba, Região Nordeste do Brasil. Biotemas, 21: 75-84.

Smith R.J., Di Minin E., Linke S., Segan D.B. \& Possingham H.P. (2010) An approach for ensuring minimum protected area size in systematic conservation planning. Biological Conservation, 143(11): 2525-2531.

Stevens P. (2014) Dinâmica da Paisagem no Geossistema do Estuário do Rio Paraíba - Extremo Oriental das Américas: estimativas de perdas de habitat e cenários de recuperação da biodiversidade. Dissertação de Mestrado, Programa de Pós-Graduação em Geografia. Universidade Federal da Paraíba, João Pessoa, Paraíba.

SUDEMA - Superintendência de Administração do Meio Ambiente (2011) Área de Proteção Ambiental (APA) de Tambaba. Disponível em: http://www.sudema.pb.gov.br./index.php?view= category\&catid=5\&option=com_joomgallery (Acessado em: 01/06/2015).

Torelli J., Rosa I.L. \& Watanabe T. (1997) Ictiofauna do Rio Gramame, Paraíba, Brasil. Iheringia, 82: 67-73.

Vettorazzi C.A. (1996) Técnicas de Geoprocessamento no Monitoramento de Áreas Florestadas. Série Técnica IPEF, 10(29): 45-51. 